\title{
Imaging of Clival Hypoplasia in CHARGE Syndrome and Hypothesis for Development: A Case-Control Study
}

\author{
(D)C.M. de Geus, (D).E.H. Bergman, (D)C.M.A. van Ravenswaaij-Arts, and (DL.C. Meiners
}

\begin{abstract}
BACKGROUND AND PURPOSE: We present the largest case series to date on basiocciput abnormalities in CHARGE syndrome (Coloboma of the eye, Heart defects, Atresia of the choanae, Retardation of growth and/or development, Genital and/or urinary abnormalities, and Ear abnormalities and/or deafness). We aimed to show that basiocciput abnormalities are common and may aid in diagnosis. We furthermore explored whether clivus size correlates with the type of chromodomain-helicase-DNA binding protein 7 gene (CHD7) mutation, which causes CHARGE syndrome, and with clinical criteria according to Blake et al and Verloes.
\end{abstract}

MATERIALS AND METHODS: We retrospectively analyzed the clivus of 23 patients with CHARGE syndrome with CHD7 mutations on MR imaging or CT. We recorded the size of the clivus, the Welcher angle, basilar invagination, and Chiari I malformations. We compared the clival size and Welcher angle of patients with CHARGE syndrome with those of 72 age-matched controls. Additionally, we tested for correlations between clivus size and mutation type or clinical criteria.

RESULTS: Eighty-seven percent of the patients with CHARGE syndrome had an abnormal clivus; $61 \%$ had a clivus $>2.5$ SD smaller than that of age-matched controls. An abnormally large Welcher angle was observed in 35\%. Basiocciput hypoplasia was found in $70 \%$, and basilar invagination, in $29 \%$. None of the patients had a Chiari I malformation. At the group level, patients with CHARGE syndrome had a smaller clivus and larger Welcher angle than controls. No significant correlation between clivus size and mutation type or clinical criteria was found.

CONCLUSIONS: Most patients with CHARGE syndrome have an abnormal clivus. This suggests that clivus abnormalities may be used as an additional diagnostic tool. Our results provide evidence that $\mathrm{CHD7}$, which is expressed in the presomitic mesoderm during somitogenesis, plays an important role in the formation of the clivus.

ABBREVIATIONS: Ba-Xs = exosphenobasion; $\mathrm{Ba}-\mathrm{Es}=$ endosphenobasion; $\mathrm{CHARGE}=$ Coloboma of the eye, Heart defects, Atresia of the choanae, Retardation of growth and/or development, Genital and/or urinary abnormalities, and Ear abnormalities and deafness; $C H D 7=$ chromodomain-helicase-DNA binding protein 7 gene. The animal homologue is Chd7. Non-italicized CHD7 (human) and Chd7 (animal) refer to the protein.

Cloboma of the eye, Heart defects, Atresia of the choanae, Retardation of growth and/or development, Genital and/or urinary abnormalities, and Ear abnormalities and deafness (CHARGE)

Received April 26, 2018; accepted after revision July 19.

From the Departments of Genetics (C.M.d.G., J.E.H.B., C.M.A.v.R.) and Radiology (L.C.M.), University of Groningen, University Medical Center Groningen, Groningen, the Netherlands.

C.M. de Geus was supported by the CHARGE Syndrome Foundation (CHARGE Syndrome Foundation pilot grant) and a personal grant of the University Medical Center Groningen. J.E.H. Bergman was supported by the Netherlands Organization for Health Research and Development (ZonMW 92003460).

Please address correspondence to L.C. Meiners, MD, Department of Radiology, University Medical Centre Groningen, University of Groningen, PO Box 30.001, NL-9700 RB Groningen, the Netherlands; e-mail: l.c.meiners@umcg.nl

- Indicates open access to non-subscribers at www.ajnr.org

三 Indicates article with supplemental on-line appendix and tables.

Indicates article with supplemental on-line photo.

http://dx.doi.org/10.3174/ajnr.A5810 syndrome is a complex disorder with multiple congenital anomalies that occurs in approximately 6 in 100,000 live births. ${ }^{1}$ First described independently by $\mathrm{Hall}^{2}$ and Hittner et $\mathrm{al}^{3}$ in 1979, the acronym CHARGE was coined by Pagon et al in $1981 .{ }^{4}$ Many more features are associated with the syndrome, such as semicircular canal dysplasia, facial nerve palsy, anosmia with or without olfactory bulb hypoplasia, delayed puberty, and cleft lip/palate. Clinical criteria have been published by Blake et $\mathrm{al}^{5}$ in 1998, Verloes ${ }^{6}$ in 2005, and Hale et $\mathrm{al}^{7}$ in 2015, which aid in the clinical diagnosis (On-line Table 1). Guidelines for cranial imaging were published by de Geus et $\mathrm{al}^{8}$ in 2017. In 2004, CHARGE syndrome was found to be caused by mutations or deletions of the chromodomain-helicase-DNA binding protein 7 gene (CHD7) gene, and molecular confirmation currently plays a pivotal role in the diagnosis. ${ }^{9}$ Pathogenic mutations in the $C H D 7$ gene usually occur de novo, though familial occurrence has been described. ${ }^{10}$

There is great phenotypic diversity in CHARGE syndrome, which 

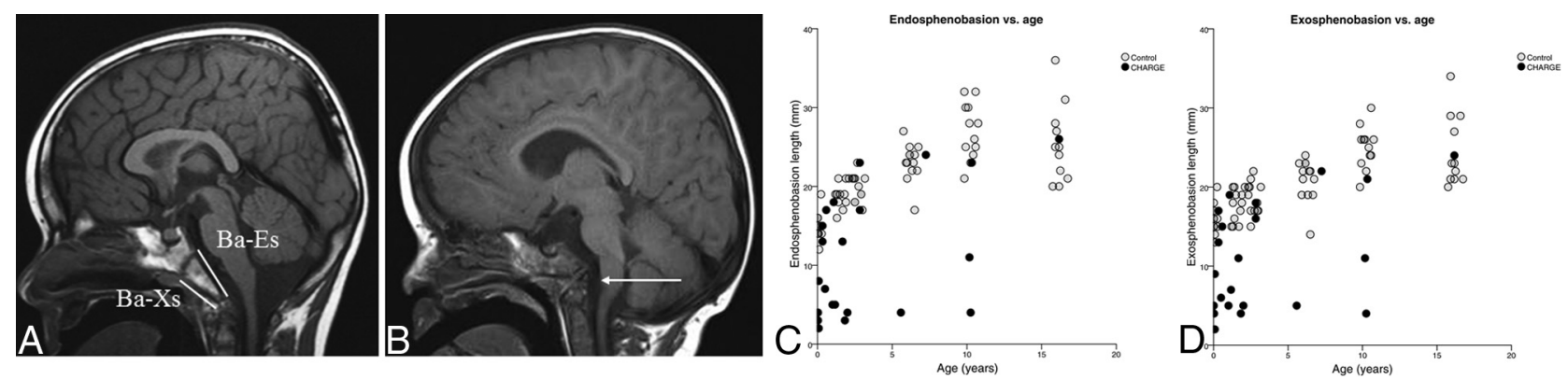

FIG 1. Clival abnormalities in CHARGE syndrome. A, Sagittal Tl scan of a 4.5-year-old boy without CHARGE syndrome. White lines show the measurement of the Ba-Es and Ba-Xs. B, A 22-month-old boy with CHARGE syndrome (patient 14). He has a hypoplastic sclerotome of the clivus (arrow) with a large Welcher angle. Although the top of the odontoid process of the dens does not extend cranially to the Chamberlain line, there is a slight angulation of the medulla oblongata without impression. $C$ and $D$, Clival size versus age. White dots show length of the $B a-E s(C)$ and $\mathrm{Ba}-\mathrm{Xs}(D)$ of the individual controls; black dots show the same parameters of individual patients with CHARGE syndrome.

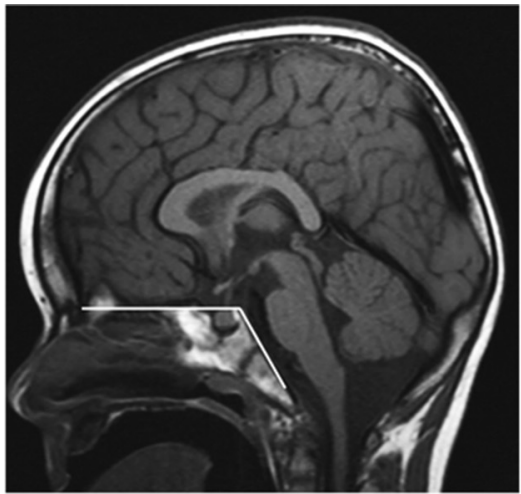

A

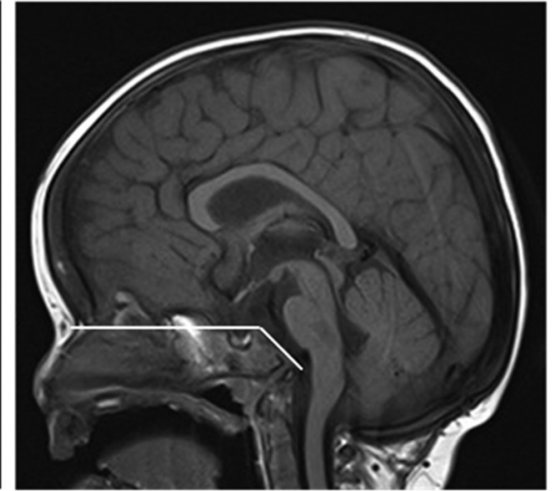

B

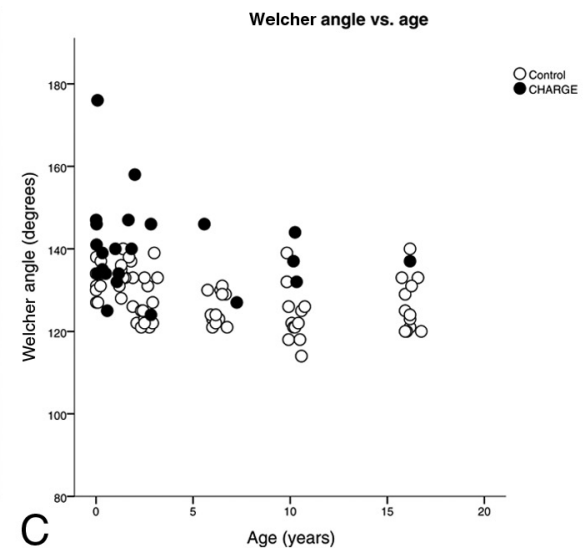

FIG 2. Platybasia in patients with CHARGE syndrome. $A$, Sagittal $\Pi 1$ scan of a 4.5 -year-old boy without CHARGE syndrome. The Welcher line is shown in white. B, A 22-month-old boy with CHARGE syndrome (patient 14). Note the large Welcher angle on the midsagittal $T 1$ scan. $C$, Welcher angle versus age. White dots show the Welcher angle of the individual controls. Black dots show the Welcher angles of individual patients with CHARGE syndrome.

complicates early diagnosis. CT and MR imaging in CHARGE may play an important role in the diagnosis by demonstrating congenital abnormalities of the labyrinth, which are present in almost all patients and can be assessed on CT and MR imaging. ${ }^{11}$ Olfactory bulb hypoplasia, cerebellar dysplasia, and other congenital brain abnormalities may be demonstrated on MR imaging, but they are not invariably present in all patients. ${ }^{12,13}$ Morphologic changes of the clivus in CHARGE syndrome were first described on neuroimaging by Fujita et al in 2009. ${ }^{14}$ A smaller size, a malformed shape, platybasia, basilar invagination, and Chiari I malformations have since been described by several authors. ${ }^{15-18}$ Normally, the body of the sphenoid occupies the upper portion of the clivus and is joined to the basilar occipital bone to form the complete clivus (Fig 1A). ${ }^{19}$ Steepness (of the clivus) may be quantified by the Welcher angle formed by a line through the frontal skull base and a line along the dorsal clivus (Fig 2A).

In the present study, we have elaborated on the previously published basiocciput findings by evaluating a large cohort of patients with molecularly proved CHARGE syndrome in comparison with age-matched controls. We further attempted to correlate clival size with mutation type and clinical criteria.

\section{MATERIALS AND METHODS \\ Patients}

The diagnosis of CHARGE syndrome was molecularly confirmed in all patients. CHD7 nonsense and frameshift mutations and larger deletions were categorized as truncating (ie, mutations leading to a nonfunctional protein or no protein at all). $\mathrm{CHD} 7$ missense mutations were categorized as nontruncating (ie, mutations leading to production of an altered protein that may have residual function). $\mathrm{CHD} 7$ splice site mutations may have truncating or nontruncating effects, and these mutations could therefore not be further categorized. All patients were scored using the Blake et $\mathrm{al}^{5}$ and Verloes ${ }^{6}$ criteria (On-line Table 1).

Neuroimaging was performed in the authors' hospital in 12 patients on a 1.5T scanner (Siemens, Erlangen, Germany) using a regular head coil. The remainder of the patients were scanned at other hospitals using different scanners (1-1.5T) of different brands using different protocols. Only patients with sagittal T1 2D TSE, 3D T1 MPRAGE, or a sagittal 2D T2 TSE imaging were included in this study. Three patients assessed at an external hospital had a CT scan with the possibility of sagittal reconstruction of a transverse CT scan of either a head scan or a mastoid scan.

All neuroimaging studies were assessed and measurements were made by an experienced pediatric neuroradiologist (L.C.M.).

\section{Controls}

Age-matched controls from 6 age groups ( 0 -3 months and 1, 2, 6 , 10 , and 16 years of age) had been scanned for various neurologic and endocrine indications, not suspicious for CHARGE syn- 
drome or skull base abnormalities, on a 1.5T MR imaging system (Siemens, Erlangen, Germany), in the authors' hospital between 2002 and 2014. All controls had sagittal 2D or 3D T1-weighted MR imaging included in the scanning protocol. The brain scan findings had been assessed as normal by various experienced neuroradiologists, and at selection, this assessment was confirmed by an experienced pediatric neuroradiologist (L.C.M.).

\section{Radiologic Analysis of the Clivus}

Anatomic definitions and measurements of the clivus were used as described by Fujita et al. ${ }^{14}$ Clivus size was quantified by measuring the exosphenobasion (Ba-Xs) and endosphenobasion (Ba-Es, Fig $1 A)$. This was done by measuring from the basion, the point of the clivus at the midpoint on the anterior margin of the foramen magnum, to the ventral (Ba-Xs) and dorsal (Ba-Es) margins of the visible synchondrosis. ${ }^{14}$ The Welcher angle is formed by the intersection between the nasion-tuberculum line and the tuberculum-basion line. ${ }^{20}$ Basioccipital hypoplasia has been defined as hypoplasia of $\geq 1$ of the 5 clival segments (sclerotomes) of the clivus (simplified from Fujita et $\mathrm{al}^{14}$ ). Basilar invagination is commonly defined as cranial displacement of $>5 \mathrm{~mm}$ of the tip of the odontoid above to the Chamberlain line. This line extends from the posterior margin of the foramen magnum anteriorly along the hard palate. Type I Chiari malformation is defined as herniation of at least 1 cerebellar tonsil $\geq 5 \mathrm{~mm}$ below the foramen magnum.

The exosphenobasion, the endosphenobasion, the Welcher angle, basilar invagination, and type I Chiari malformation were measured.

\section{Statistical Analysis}

The scans of the patients with CHARGE syndrome were compared with the findings on sagittal T1-weighted MR images of 72 controls in 6 age groups: $0-3$ months and 1, 2, 6, 10, and 16 years of age.

Measurements of Ba-Es, Ba-Xs, and Welcher angle in controls were used to calculate age-specific mean and SD values. Patient measurements were compared with age-specific mean control values. A clivus was determined to be abnormally small if it was $>2.5$ SDs below its age-specific control. The Welcher angle was determined to be abnormally large if it was $>2.5$ SDs above its age-dependent control value.

Because the Ba-Es, Ba-Xs, and the Welcher angle were highly correlated (On-line Table 2), we orthogonalized the data with factor analysis. The first factor was then modeled with nonlinear regression on the normal data. To control for bias due to the difference in age distribution of patients with CHARGE syndrome and controls, we computed the observed minus the predicted values, which were then tested with a 2-sample $t$ test (for additional statistical methods, see the On-line Appendix). A 2-sided Fisher exact test was performed to examine correlations between the size of the clivus and the type of mutation (truncating versus nontruncating), the presence of choanal atresia or coloboma, and satisfaction of the criteria of Verloes ${ }^{6}$ or Blake et $\mathrm{al}^{5}$ (listed in On-line Table 1). No $t$ test was performed for the criteria of Hale et $\mathrm{al}^{7}$ because all patients satisfied these criteria.
Table 1: Characteristics for 23 patients with CHARGE syndrome in our case series

\begin{tabular}{|c|c|}
\hline Characteristics & \\
\hline Median age (range) & $20 \mathrm{Mo}$ (3 days to $16 \mathrm{yr}$ ) \\
\hline Males & 15 \\
\hline Females & 8 \\
\hline \multicolumn{2}{|l|}{ Criteria of Blake et $\mathrm{al}^{5}$ satisfied $^{\mathrm{a}}$} \\
\hline Typical CHARGE syndrome & 12 \\
\hline Negative & 8 \\
\hline Missing data & 3 \\
\hline \multicolumn{2}{|l|}{ Criteria of Verloes $^{6}$ satisfied $^{a}$} \\
\hline Typical CHARGE syndrome & 12 \\
\hline Partial CHARGE syndrome & 0 \\
\hline Atypical CHARGE syndrome & 5 \\
\hline Negative & 0 \\
\hline Missing data & 6 \\
\hline Criteria of Hale et $\mathrm{al}^{7}$ criteria satisfied ${ }^{a}$ & 23 \\
\hline \multicolumn{2}{|l|}{ Mutation type $(n=23)^{\mathrm{b}}$} \\
\hline $\begin{array}{l}\text { Truncating (nonsense, frameshift, } \\
\text { deletion) }\end{array}$ & 17 \\
\hline Nontruncating (missense) & 2 \\
\hline Splice site & 4 \\
\hline
\end{tabular}

a See On-line Table 1.

${ }^{\mathrm{b}}$ Truncating mutations (nonsense or frameshift) lead to a decrease in CHD7 protein Nontruncating (missense) mutations lead to production of an altered CHD7 protein, which may have residual function. Splice site mutations may have truncating or nontruncating effects.

\section{RESULTS}

In total, 23 patients with an age range of 3 days to 16 years (median age, 20 months) were included in this study. Table 1 summarizes the patients' clinical criteria according to Blake et al, Verloes, and Hale et al and their type of $C H D 7$ mutation. The full spectrum was represented in patients with both clinically typical and atypical CHARGE syndrome.

Figure $1 C$, $-D$ summarizes the lengths of the Ba-Es and Ba-Xs for patients and controls with increasing age. For 2 patients, the presence of basilar invagination could not be reliably determined (patients 13 and 20 in On-line Table 3). Most patients with CHARGE syndrome $(87 \%, 20 / 23)$ had a clivus that was small or had abnormal morphology or both. Fourteen patients had a clivus of $>2.5$ SDs smaller than in their age-matched controls $(61 \%$, $14 / 23)$. In 8 patients $(35 \%, 8 / 23)$, an extra synchondrosis was seen. Just more than two-thirds $(70 \%, 16 / 23)$ of the patients with CHARGE syndrome showed very short clivi with loss of the normal triangular shape (basiocciput hypoplasia), which was further illustrated by 9 of them having a Welcher angle of $\geq 2.5$ SDs above that in controls, indicating platybasia (39\%, 9/23; Fig 2C). The Welcher angle varied between $124^{\circ}$ and $176^{\circ}$ (mean $140^{\circ}$, SD $\left.11.2^{\circ}\right)$

The results for the comparison at the group level are shown in On-line Tables 2 and 4 and the On-line Figure. Most of the patients with CHARGE syndrome showed a reduced value in factor 1. Factor 1 had a positive correlation with the Ba-Es and Ba-Xs and a negative correlation with the Welcher angle. Despite some patients with CHARGE syndrome having clearly normal values, as a group they had significantly lower values $\left(P=6 \times 10^{-6}\right)$, which correspond with a smaller Ba-Es and $\mathrm{Ba}$-Xs and larger Welcher angles.

Six $(29 \%, 6 / 21$, missing data $n=2)$ patients with CHARGE syndrome showed basilar invagination. In 2 of these patients, a minor impression of the craniovertebral junction on the medulla 
Table 2: Correlations between clivus size and clinical parameters

\begin{tabular}{|c|c|c|c|}
\hline \multirow[b]{2}{*}{ Variable } & \multicolumn{2}{|c|}{$\begin{array}{c}\text { Size } \\
\text { of Clivus }\end{array}$} & \multirow[b]{2}{*}{$\begin{array}{c}P \\
\text { Value }\end{array}$} \\
\hline & Normal & $\begin{array}{c}<2.5 \text { SDs } \\
\text { Compared } \\
\text { with Controls }\end{array}$ & \\
\hline \multicolumn{4}{|l|}{$\begin{array}{l}\text { Truncating mutation } \\
\quad(\text { total } n=19)^{\mathrm{a}}\end{array}$} \\
\hline+ & 5 & 12 & .12 \\
\hline- & 2 & 0 & \\
\hline \multicolumn{4}{|c|}{ Presence of choanal atresia } \\
\hline+ & 1 & 4 & .33 \\
\hline- & 8 & 10 & \\
\hline \multicolumn{4}{|c|}{$\begin{array}{l}\text { Presence of coloboma } \\
\text { (total } n=22)^{\mathrm{b}}\end{array}$} \\
\hline+ & 4 & 8 & .36 \\
\hline- & 5 & 5 & \\
\hline \multicolumn{4}{|l|}{ 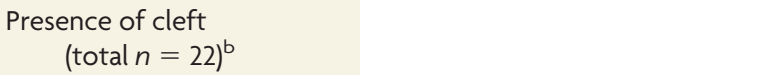 } \\
\hline+ & 3 & 2 & .61 \\
\hline- & 6 & 11 & \\
\hline \multicolumn{4}{|c|}{ Verloes $^{6}$ criteria satisfied $^{c}$} \\
\hline+ & 4 & 8 & 1.00 \\
\hline- & 2 & 3 & \\
\hline \multicolumn{4}{|c|}{ Blake et al $^{5}$ criteria satisfied $^{c}$} \\
\hline+ & 3 & 5 & 1.00 \\
\hline- & 4 & 8 & \\
\hline
\end{tabular}

Note:-_ indicates yes; -, no.

${ }^{a}$ Four patients had a splice site mutation and could not be classified as either truncating or nontruncating.

${ }^{\mathrm{b}}$ For 1 patient, no data regarding presence of coloboma were available. For 1 patient, no information regarding cleft lip/palate was available.

'See also On-line Table 1.

oblongata was suggested (see Fig $1 B$ for an example). None of the patients exhibited herniation of the cerebellar tonsils.

Table 2 shows the correlation among clivus size, clinical criteria, and type of mutation. No significant correlation was found between the size of the clivus in the patients with CHARGE syndrome and the mutation type (truncating versus nontruncating), occurrence of facial clefts, ocular coloboma, atresia of the choanae, or satisfaction of the Verloes or Blake et al criteria.

\section{DISCUSSION}

In this study, the presence of clival abnormalities was assessed in a large group of patients with CHARGE syndrome and compared with that in healthy controls.

Clival abnormalities in CHARGE syndrome have been published previously. Fujita et $\mathrm{al}^{14}$ were the first to publish examples of basioccipital hypoplasia in $7 / 8$ patients $(88 \%)$ and associated basilar invagination in $5(63 \%)$. Furthermore, one of their patients exhibited a Chiari I malformation and syringomyelia. Natung et $\mathrm{al}^{15}$ described a case with a short clivus, fused cervical vertebrae, occipitalization of the atlas, and basilar invagination. Hoch et $\mathrm{al}^{16}$ found skull base hypoplasia in 9/10 and a dorsally angulated clivus in 7/10 patients. Mahdi and Whitehead ${ }^{17,18}$ described a child with a coronal clival cleft in 2017 and recently published a study consisting of 15 genetically and clinically confirmed CHARGE cases, in which they reported a coronal cleft in $13(87 \%)$ patients and clival hypoplasia without a cleft in the remaining 2 patients.

Although we did not particularly assess the coronal cleft, the prevalence of clival abnormalities and/or skull base hypoplasia in these articles is similar to our numbers. We found that 20/23 patients with CHARGE syndrome (87\%) had an abnormal clivus, either in morphology or size. At the group level, patients with CHARGE syndrome had a smaller clivus and larger Welcher angle (On-line Figure). However, only 14/23 (61\%) had an abnormally small clivus, defined as $>2.5$ SDs smaller than that of agematched controls (On-line Table 3 and Fig 1). Basilar invagination was seen in only 6 patients $(29 \%, 6 / 21$, missing data in 2 patients), with only 2 of these patients showing a minimal impression on the ventral medulla oblongata. None of the patients in the present study had a Chiari I malformation. If we combined our study and the above-mentioned 2 case series, 51 of 56 patients with CHARGE syndrome (91\%) had clival abnormalities and/or skull base hypoplasia, underscoring the potential of this feature as a diagnostic tool in CHARGE syndrome.

However, because all of these case series represent nonrandomly selected samples, there is a danger of overestimation. All samples may be biased toward the more severe end of the clinical spectrum because more severely affected patients may be more likely to undergo cerebral imaging. Our data do not show correlation between the severity of the disorder (satisfaction of clinical criteria) and the presence of clival abnormalities. In fact, in our case series, a large number of patients were atypical on the Verloes criteria (5/17) or negative on the Blake et al criteria (8/20), yet clival abnormalities were found in most. This finding underscores the importance of clival abnormalities on imaging in supporting the diagnosis, especially in mildly affected patients.

Basilar invagination in patients with CHARGE syndrome may be of clinical importance because it may cause compression of the medulla with ensuing clinical symptoms. No obvious neurologic symptoms that could be attributed to the basilar invagination were reported in the clinical data of the 2 patients who showed possible involvement of the medulla (patients 14 and 15 in Online Table 3). Only 1 of the patients in the series of Fujita et $\mathrm{al}^{14}$ had neurologic sequelae, but she was reported to have syringomyelia in addition to basilar impression.

In our study, hypoplasia of the clivus was suggested as an allor-nothing event: If hypoplasia was present, the degree of hypoplasia was severe (Ba-Es of -4 to -10 SDs smaller than in controls, Fig 1 and On-line Table 3 ). The high variability and incomplete penetrance of specific features are well-known aspects of CHARGE syndrome. ${ }^{21}$ CHARGE syndrome is exclusively caused by mutations in CHD7. The chromodomain helicase DNA-binding protein 7 (protein CHD7) ${ }^{9}$ is essential in embryologic development, and mutations in $\mathrm{CHD} 7$ result in a wide range of features with incomplete penetrance. Much of the clinical variability is still unexplained, though there is some correlation between clinical severity and mutation type: Patients with a missense CHD7 mutation generally have a milder presentation of clinical features. ${ }^{22}$ In our cohort, no correlations were found between clivus length and mutation type, satisfaction of all CHARGE criteria, or specific symptoms. Milder missense mutations are, however, fairly rare in CHARGE syndrome. This is reflected in our study because only $2 / 23$ patients had a missense mutation.

The precise function of the $\mathrm{CHD} 7$ protein in the formation of 
the skull base is unknown. CHD7 is expressed in the presomitic mesoderm during somitogenesis, ${ }^{23}$ in which it plays a role in controlling left-right symmetry. Somitogenesis is an important process in the formation of the clivus, which is formed from 4 occipital somites through a complicated process. In this process, fusion of the first 3 somites creates the rostral basiocciput. ${ }^{24}$ After formation of a transient sclerotome called the proatlas, parts of the fourth somite then form the basion. Chd7 knockdown zebrafish exhibit irregularly shaped vertebrae, ${ }^{23,25}$ supporting the role of CHD7 in somitogenesis. The altered anatomy of the clivus in many patients with CHARGE syndrome may therefore reflect errors in somitogenesis due to faulty CHD7 signaling.

This study has several limitations. It was based on retrospective assessment of MR imaging and CT scans obtained at different hospitals using different scanning protocols and image parameters. Nevertheless, a sagittal MR imaging scan or a sagittal CT reconstruction, on which the clivus could be assessed, was always available. However, in 2 cases, the clivus was difficult to assess. An altered anatomy of the remainder of the skull base, also described by Natung et al, ${ }^{15}$ made the definition of clival borders difficult in several cases. Extreme clival hypoplasia also limited accurate measurements.

\section{CONCLUSIONS}

This is the largest case-control series on clivus abnormalities in CHARGE syndrome, to our knowledge. Although the clinical relevance of clival hypoplasia and platybasia in CHARGE syndrome is not yet clear, the results of this study confirm the suggestion by Mahdi and Whitehead ${ }^{18}$ that besides the well-known labyrinthine anomalies and hypo- or aplasia of the olfactory bulb, ${ }^{26}$ clival abnormalities may provide an important extra clue for the diagnosis of CHARGE syndrome in neuroimaging studies. We hypothesize that CHD7 may play an important role in the development of clival hypoplasia.

\section{ACKNOWLEDGMENTS}

We thank J. Senior for editing the manuscript and G.J. te Meerman, biostatistician, for his valuable help with the statistical analysis.

Disclosures: Christa M. de Geus—RELATED: Grant: CHARGE Syndrome Foundation pilot grant.* Grant: University Medical Center Groningen GrAGIKO grant. Jorieke E. H. Bergman—RELATED: Grant: Netherlands Organization for Health Research and Development, Comments: grant no. 92003460 to J.E.H. Bergman for a PhD (the PhD was obtained between 2007 and 2011).* *Money paid to the institution.

\section{REFERENCES}

1. Janssen N, Bergman JE, Swertz MA, et al. Mutation update on the CHD7 gene involved in CHARGE syndrome. Hum Mutat 2012;33: 1149-60 CrossRef Medline

2. Hall BD. Choanal atresia and associated multiple anomalies. J Pediatr 1979;95:395-98 CrossRef Medline

3. Hittner HM, Hirsch NJ, Kreh GM, et al. Colobomatous microphthalmia, heart disease, hearing loss, and mental retardation: a syndrome. J Pediatr Ophthalmol Strabismus 1979;16:122-28 Medline

4. Pagon RA, Graham JM Jr, Zonana J, et al. Coloboma, congenital heart disease, and choanal atresia with multiple anomalies: CHARGE association. J Pediatr 1981;99:223-27 CrossRef Medline
5. Blake KD, Davenport SL, Hall BD, et al. CHARGE association: an update and review for the primary pediatrician. Clin Pediatr (Phila) 1998;37:159-73 CrossRef Medline

6. Verloes A. Updated diagnostic criteria for CHARGE syndrome: a proposal. Am J Med Genet A 2005;133A:306-08 Medline

7. Hale CL, Niederriter AN, Green GE, et al. Atypical phenotypes associated with pathogenic $\mathrm{CHD} 7$ variants and a proposal for broadening CHARGE syndrome clinical diagnostic criteria. Am J Med Genet A 2016;170A:344-54

8. de Geus CM, Free RH, Verbist BM, et al. Guidelines in CHARGE syndrome and the missing link: cranial imaging. Am J Med Genet C Semin Med Genet 2017;175:450-64 CrossRef Medline

9. Vissers LE, van Ravenswaaij CM, Admiraal R, et al. Mutations in a new member of the chromodomain gene family cause CHARGE syndrome. Nat Genet 2004;36:955-57 CrossRef Medline

10. Jongmans MC, Hoefsloot LH, van der Donk KP, et al. Familial CHARGE syndrome and the $\mathrm{CHD} 7$ gene: a recurrent missense mutation, intrafamilial recurrence and variability. Am J Med Genet A 2008;146:43-50 Medline

11. Morimoto AK, Wiggins RH 3rd, Hudgins PA, et al. Absent semicircular canals in CHARGE syndrome: radiologic spectrum of findings. AJNR Am J Neuroradiol 2006;27:1663-71 Medline

12. Yu T, Meiners LC, Danielsen K, et al. Deregulated FGF and homeotic gene expression underlies cerebellar vermis hypoplasia in CHARGE syndrome. Elife 2013;2:e01305 CrossRef Medline

13. Leboucq N, Menjot de Champfleur N, Menjot de Champfleur S, et al. The olfactory system. Diagn Interv Imaging 2013;94:985-91 CrossRef Medline

14. Fujita K, Aida N, Asakura Y, et al. Abnormal basioccipital development in CHARGE syndrome. AJNR Am J Neuroradiol 2009;30: 629-34 CrossRef Medline

15. Natung T, Goyal A, Handique A, et al. Symmetrical chorioretinal colobomata with craniovertebral junction anomalies in CHARGE syndrome: a case report with review of literature. J Clin Imaging Sci 2014;4:5 CrossRef Medline

16. Hoch MJ, Patel SH, Jethanamest D, et al. Head and neck MRI findings in CHARGE syndrome. AJNR Am J Neuroradiol 2017;38: 2357-63 CrossRef Medline

17. Mahdi E, Whitehead MT. Coronal clival cleft in CHARGE syndrome. Neuroradiol J 2017;30:574-77 CrossRef Medline

18. Mahdi ES, Whitehead MT. Clival malformations in CHARGE syndrome. AJNR Am J Neuroradiol 2018;39:1153-56 CrossRef Medline

19. Chapman PR, Bag AK, Tubbs RS, et al. Practical anatomy of the central skull base region. Semin Ultrasound CT MR 2013;34:412-35 CrossRef Medline

20. Smoker WR. Craniovertebral junction: normal anatomy, craniometry, and congenital anomalies. Radiographics 1994;14:255-77

21. Bergman JE, Janssen N, Hoefsloot LH, et al. CHD7 mutations and CHARGE syndrome: the clinical implications of an expanding phenotype. J Med Genet 2011;48:334-42 CrossRef Medline

22. Bergman JE, Janssen N, van der Sloot AM, et al. A novel classification system to predict the pathogenic effects of $\mathrm{CHD} 7$ missense variants in CHARGE syndrome. Hum Mutat 2012;33:1251-60 CrossRef Medline

23. Jacobs-McDaniels NL, Albertson RC. Chd7 plays a critical role in controlling left-right symmetry during zebrafish somitogenesis. Dev Dyn 2011;240:2272-80 CrossRef Medline

24. Müller F, O’Rahilly R. Segmentation in staged human embryos: the occipitocervical region revisited. J Anat 2003;203:297-315 CrossRef Medline

25. Patten SA, Jacobs-McDaniels NL, Zaouter C, et al. Role of Chd7 in zebrafish: a model for CHARGE syndrome. PLoS One 2012;7:e31650 CrossRef Medline

26. Blustajn J, Kirsch CF, Panigrahy A, et al. Olfactory anomalies in CHARGE syndrome: imaging findings of a potential major diagnostic criterion. AJNR Am J Neuroradiol 2008;29:1266-69 CrossRef Medline 